Research Article

\title{
Pricing Strategies in the Remanufacturing Market for the Uncertain Market Size in the Second Period
}

\author{
Liurui Deng ${ }^{1}$ and Shenggang Yang ${ }^{2}$ \\ ${ }^{1}$ College of Economics and Management, Hunan Normal University, Changsha 410081, China \\ ${ }^{2}$ College of Finance and Statistics, Hunan University, Changsha 410082, China
}

Correspondence should be addressed to Liurui Deng; purplerosed@yahoo.com

Received 20 December 2015; Accepted 17 March 2016

Academic Editor: Dimitris Fotakis

Copyright (c) 2016 L. Deng and S. Yang. This is an open access article distributed under the Creative Commons Attribution License, which permits unrestricted use, distribution, and reproduction in any medium, provided the original work is properly cited.

\begin{abstract}
Our main endeavor is to investigate the effect of the uncertain market size in the second period on the pricing strategies in the remanufacturing market. Observing the previous research, we find that the market size in the second period is always supposed to be certain. However, there is substantial empirical and experimental evidence that the market size in reality deviates from this assumption. In fact, though the market size in the first period is definitized, it is difficult to confirm the change of the market scale in the second period, since this change is affected by all kinds of elements, such as the awareness of environmental protection, some consumers' psychological factors, and the related governments' policies. Hence, we pay attention to the case in which the change rate of the market scale in the second period is random variable. We suppose that this rate satisfies uniform distribution on $[0,2]$. Underlying this assumption, we further provide an insight into the game-playing relationship between original equipment manufacturers (OEMs) and remanufacturers. Moreover, we delicately and subtly incorporate the game theory, stochastic analysis, adversarial risk analysis (ARA), and optimization methods into the pricing strategies in the remanufacturing market. Last but not least, considerable efforts and attempts have been made to subtly test the sensitivity of an optimal solution to the different parameters.
\end{abstract}

\section{Introduction}

(1) Research Background. The flow of products in supply chain goes upstream to downstream, such as from the suppliers' supplier to customers' customer. Shorter product life cycles and consumers' consumption behaviors result in faster products flows and subsequently faster generation of waste and depletion of natural resources (see [1]). Varel states that manufacturing generates excess $60 \%$ annual nonhazards waste (see [2]). The contradiction between social and economic development and environmental protection is more and more sharp, which makes more and more people and governments pay attention to balancing economic and social development with environmental protection. Both the 1992 Rio Earth Summit and Brundtland Report sharply and frankly declared that coordinating the environmental protection with the social and economic development is one of the most essential challenges in security long-term sustainability (see [3]). Meanwhile, increasing stringent legislation is established to compel enterprises to reduce the influence of products and manufacturing process on the environment. For example, producer responsibility legislation demands that producers should recover used products to reduce landfill. Such pressure, incorporating mounting competition due to global industry activity, challenges companies to strengthen environmental consciousness and give rise to the drive collecting and remanufacturing returned/used products for extending their usable lives in order to reduce waste and conserve natural resource (see [4]).

Remanufacturing is an industrial process in which used products are brought to a "like-new" functional state with warranty to match (see $[5,6])$. In other words, remanufacturing means that a product is updated and reprocessed in this process. In more detail, remanufacturing includes disassembly, clearing inspection, reconditioning, and reassembly. Remanufacturing is both more profitable and less harmful to the environment than conventional manufacturing due to the decrements in the raw materials demanded, production 
processes, and production costs (see [7]), such as the levels of virgin material, landfill, energy, specialised labour, and machine time (see $[8,9]$ ). Giuntini and Gaudette confirm that remanufactured products costs are $40-65 \%$ less than new products to produce; thus, remanufactured products' prices are typically $30-40 \%$ lower than new products (see [10]). Globally, remanufacturing can save about 120 trillion BTUs per year of energy, accounting for about 16 million barrels of crude oil and about US\$500 million in energy cost. Annual material saved from remanufacturing activities worldwide is 14 million tonnes per year, which is equivalent to fully loaded railway train 1650 miles long (see [11]).

The previously mentioned appealing advantages of remanufacturing motive the remanufacturing industry to burgeon. In 1996, remanufacturing industry reached US\$53 billion which consisted of approximately 73,000 remanufacturing companies (see [9]). These sale figures were on a par with the American steel industry. However, the direct employment figure of 48,000 was twice that of the American steel industry and equaled that of the consumer durable industry (see [11]). Global Industry Analysts affirm that the global automotive remanufacturing industry is rapidly growing and is predicted to reach US $\$ 104.8$ billion by the end of 2015 (see [12]). The boom of the remanufacturing industry gives the related research an incentive and thus the problems about remanufacturing have been stressed in several studies. In the next content of this paper, we will briefly review some related literatures without being completed.

(2) Literature Review. Although the pricing strategy in the remanufacturing market is relatively a new term, there are plenty of applausive achievements which abundant researchers manage to obtain [13]. Savaskan et al. discuss the problem of choosing the appropriate reverse channel structure for the collection of used products from customers (see [14]). Jaber and El Saadany create the production, remanufacture, and waste disposal model with lost sales (see [15]). Agrawal et al. experimentally investigate the effect of remanufactured products on the perceived value of new products (see [16]). King et al. provide an insight into the importance of remanufactured products for reducing waste and protecting environment (see [17]). Some researchers focus on the policy influences. Webster and Mitra examine the impact of take-back laws within a manufacturer/remanufacturer competitive framework and develop a general two-period model to investigate questions of interest to policy-makers in government and managers in industry (see [11]). Based on the general research, many investigators begin to explore dynamic models, especially two-period models. Yuksel addresses the design of automobile engines for the remanufacture with quality function deployment (see [18]). Ferrer and Swaminathan characterize the production quant self-selection and explore the effect of various parameters in the Nash equilibrium on the duopoly environment (see $[19,20])$. Meanwhile, other researchers are more interested in the pricing strategies for dynamic models. Wun pays attention to the effects of disassemblability and interchangeability on the price competition (see [21, 22]). Besides, he considers price and service between new and remanufactured products (see [23]). Mitra focuses attention on revenue management for remanufactured products and develops a pricing model to maximize the expected revenue from the recovered products (see [24]). In view of service competition, Deng builds a Stackelberg model which contains an original manufacturer, a recycler, and a remanufacturer and further obtains the equilibrium decision of closed-loop supply chain. Based on this strategy model, Deng demonstrates how two different subsidies to utilization rate of raw materials, the service level, and the demand of products impact on the terminal decision (see [25]).

It is noteworthy that the previously mentioned research is based on Stackelberg model. However, beyond the pricing strategies in the remanufacturing market, the classical Stackelberg model believes that since OEMs are the monopoly position, they know the pricing strategy of remanufacturers in the second period. However, the development of remanufacturing industry shakes OEMs monopoly position and makes remanufacturers become stronger and stronger. So, in fact, OEMs do not know the pricing strategy of remanufacturers in the second period. In particular, the rate of recovery changes because of development of remanufacturing industry, improvement of new machines, disassemblability, or other unpredicted reasons. As for OEMs, it is impossible to accurately know the rate of recovery. Thus, OEMs do not know the exact pricing strategies of remanufacturers. Meanwhile, the unit production cost is not fixed but rather changed. Production technology and process improvement cause this cost to change. Similar to OEMs, as for remanufacturers, they have no way to know exactly the unit production cost. The major violation of the traditional Stackelberg model inspires Deng and Ma to build the remanufacturers and the OEMs 1-order adversarial risk analysis (ARA) models, since there exits the game relationship between the OEMs and the remanufacturers in the reality and the above unknown elements by the opponents (see [26]).

The motivation of Deng's ARA models of OEMs and remanufacturers makes this paper reveal that the pricing strategies in the remanufacturing market for the uncertain market scale in the second period. Differing from Deng's previous research, in this paper, through observing the previous research, we find that the predominant literatures have another underlying assumption that the market size in the second period is certain. However, there is substantial empirical and experimental evidence that the market size in reality deviates from this assumption. In fact, though the market size of the first period is definitized, it is difficult to confirm the change of the market scale in the second period, since this change is affected by all kinds of elements, such as people's environmental awareness, some consumers' psychological factors, the development of remanufacturing industry, and the related governments' policies.

Noting the above shortcoming of the traditional pricing strategy, we focus on the pricing strategies of OEMs and remanufacturers under uncertain market size in the second period in this paper. The uncertain market scope in the second period brings us the diverse obstacle from the previous work that the optimal pricing strategy becomes a stochastic optimization problem rather than a real one. We tackle this 
challenge in the approach in which we make great efforts to incorporate stochastic analysis, Stackelberg model, and adversarial risk analysis models into discussing the optimal pricing strategies. Our considerable attempts and efforts have been made to indicate an explicit expression for the optimal pricing strategies. We further provide an insight into the sensitivity of optimal explicit solutions to the different parameters, $\rho$ and $\beta$, in order to reveal the impact of the various parameters on the optimal strategies in powerfully numerical means.

The rest of this paper is organized as follows. We first describe the remanufacturing market and introduce the related parameters in Section 2. Then, Section 3 presents the pricing strategies of the remanufacturer and the OEM. In this section, we firstly build the pricing strategy model of remanufacturers. These pricing strategies are taken into account in two cases, the high pricing strategy and the low pricing strategy. Based on these pricing strategies of the remanufacturer, we further indicate the pricing strategy models of OEMs. According to the pricing strategies of the remanufacturer, the pricing strategies of the OEM are divided into two different strategies which are the OEM's responses to the high and low pricing strategies of the remanufacturer. In Section 4, we summarize the concrete strategies studied earlier. Sequently, through testing the sensitivity of the optimal pricing strategies to the different parameters, $\rho$ and $\beta$, we investigate all kinds of paraments' influence on the pricing strategies with the numerical method in Section 5. Later, Section 6 summarizes our important theoretical and numerical contributions about the optimal pricing strategy. At last, namely, in Section 7, we propose some interesting and meaningful problems which we will explore in the future.

\section{The Description of the Remanufacturing Market and the Related Parameters}

Before exploring the model, it is necessary to describe the remanufacturing market and introduce the related paraments.

\subsection{The Description of the Remanufacturing Market. We first} present the remanufacturing market. Usually, we suppose that there are two kinds of the manufacture, original equipment manufacturers (OEMs) and remanufacturers. There is a game relationship between them. The pricing strategies will directly affect each other's market share and profit. Meanwhile, OEMs' design for disassembly influences on the costs of OEMs and remanufacturers. To be specific, high disassemblability makes it easy to repair, clean, and inspect OEMs. Moreover, high disassemblability reduces the recover cost of remanufacturers. However, the design for high disassemblability increases the fixed cost of OEMs. So, in order to save fixed cost and raise the remanufacturers' cost, OEMs always will choose to design for low disassembly. This measure makes remanufacturers erode the competitiveness and OEMs strengthen competitiveness.

The market is divided into two segments, which are the primary and green segments. Accordingly, the primary market is composed of primary consumers and the green market consists of green consumers (see [27, 28]). Primary consumers believe that the new product has higher value than the remanufactured product. Nevertheless, green consumers are sure that the remanufactured product has the same value as the new product. So, green consumers prefer the remanufactured product to the new product. Because there is no remanufactured product in the first period, the primary and green consumers are not different in this period. However, in the second period, the green consumers are more willing to buy the green product than the new product, since the green product is beneficial for environment.

Noticing that many elements impact on pricing strategies, such as the proportion of green consumers in the whole market, the rate of the used product being available to be remanufactured, and the change of the market size, we set the necessary parameters. In this paper, we consider that parameters are fixed except that the design for disassembly has two levels.

2.2. The Introduction of the Related Parameters. Sequently, we introduce the relevant parameters. The rate of the used product being available to be remanufactured is noted as $\gamma$. Suppose that the market has two periods. The first period consists of $A$ consumers, in which green and primary consumers are indifferent, since there is no remanufactured product. Therefore, in this period, the market is the primary market. The second period includes $\Delta A$ consumers. $\Delta$ represents the change rate of the market scale in the second period compared with the market size in the first period. In particular, assume that $\Delta$ follows uniform distribution on $[0,2]$. In this period, the market is divided into the primary segment and the green segment. The primary segment consists of primary consumers who are willing to pay for green products $\rho$ times as high as primary ones. That is, if we let the price of a new product $p_{n}$ be accepted by primary consumers in the second period, then the primary consumers prefer to pay $\rho p_{n}$ or less money for a green product. Otherwise, the primary consumers will not buy the green product. Meanwhile, green consumers think that green products are the same as primary ones. So, the green consumers prefer green products. Assume that the percentage of green consumers in the whole market is $\beta$ and the primary consumers' proportion is $1-\beta$. The quantity of the remanufactured product is restricted by the quantity of the new product in the first period.

We suppose that the utility of consumers in the first period is $U_{1}=\theta-p_{1}$, where $\theta \sim$ Uniform $[0,1]$ (please see [16]) and $p_{1}$ is the price of the new product in the first period. The utility of primary and green consumers is, respectively, $U_{n}=\theta-p_{n}$ and $U_{r}=\rho \theta-p_{r}$, where $p_{r}$ is the price of the green product in the second period. $q_{r}, q_{n}$, and $q_{1}$ are, respectively, the demand of the remanufactured product, the demand of the new product in the second period, and the demand of the new product in the first period. Further, suppose that $\gamma$ is the proportion in the collected end-life-cycle products which are used by remanufacturers. The levels of disassemblability are high $H$ and low L. Accordingly, OEM's different unit production costs are $c_{L}$ and $c_{H}$ and the remanufacturer's different recovery costs are $w_{L}$ and $w_{H} \cdot T_{l}$ and $T_{H}$ are the fixed 
costs of OEMs. The remanufactures' pricing strategies are high $G$ and low $S$. The rate of discount is $\delta$.

\section{The Relevant Models}

Here, we take Stackelberg model into account. So, firstly, it is needed to provide an insight into the pricing strategies of the remanufacturer which consist of the low and high pricing strategies. Then, relying on the pricing strategy of the remanufacturer, we investigate the pricing strategies of OEMs dealing with ones of the remanufacturer. That is, we, respectively, consider the pricing strategy of OEMs for low pricing strategy of the remanufacturer and the pricing strategy of OEMs for high pricing strategy of the remanufacturer.

3.1. The Model of the Remanufacture. Now, it is needed to think that the remanufacturing problem under restricted condition is as follows:

$$
\begin{aligned}
\max & E\left[\Pi_{r}^{i, j}\right]=\max E\left[\delta\left(p_{r}-w_{i}\right) q_{r}^{j}\right], \\
\text { s.t. } & q_{r}^{j}<\gamma q_{1},
\end{aligned}
$$

where $i \in\{L, H\}, j \in\{S, G\}$.

3.1.1. The Low Pricing Strategy of the Remanufacturer. We firstly think about the low pricing strategy of the remanufacturer, that is, $p_{r} \leq \rho p_{n}$. At this time, since the price of the green products is lower than the price of one expected by the primary consumers, some primary consumers prefer the green product. Hence, in the second period, the remanufacturers compete with the OEMs and the price of the new product affects the profit of remanufacturers. On the other hand, the price of the new product in the first period impacts on the demand of the green product and further impacts on the profit of the remanufacturers. The relationship between the optimal price strategies of the remanufacturers is displayed in the following proposition.

Proposition 1. Consider

$$
\begin{aligned}
& p_{r, i, S}^{*}\left(p_{1}, p_{n}\right) \\
& = \begin{cases}p_{r, i, S, 1}^{*}\left(p_{1}, p_{n}\right) & p_{r} \in\left[\min \left\{0, K, \rho p_{n}\right\}, \min \left\{K, \rho p_{n}\right\}\right] \\
p_{r, i, S, 2}^{*}\left(p_{1}, p_{n}\right) & p_{r} \in\left[\min \left\{K, \rho p_{n}\right\}, \rho p_{n}\right],\end{cases}
\end{aligned}
$$

where

$$
\begin{aligned}
p_{r, i, S, 1}^{*}\left(p_{1}, p_{n}\right)= & \rho p_{n} I_{L=M}+p_{r}^{(1)} I_{M^{2}-4 L N>0} \\
& +p_{r}^{(2)} I_{M^{2}-4 L N=0}+p_{r}^{(3)} I_{M^{2}-4 L N<0}, \\
p_{r, i, S, 2}^{*}\left(p_{1}, p_{n}\right)= & p_{r}^{(4)}=\frac{w_{i} C-B}{2 C} \\
= & \frac{1}{2}\left(\frac{\rho\left(\beta+\chi p_{n}\right)}{\beta \rho+\chi}+w_{i}\right),
\end{aligned}
$$

$C, B, K, L, M$, and $N$ are parameters depending on $p_{1}, p_{n}, \gamma, \rho$, $\beta$. And, $p^{(1)}, p^{(2)}$, and $p^{(3)}$ are the different pricing strategies of the remanufacturers depending on $p_{1}, p_{n}, \gamma, \rho, \beta$ in the different parameters' ranges.

The proof and the description of parameters and pricing strategies are displayed in Appendix A. This proposition displays the low pricing strategy of the remanufacturer.

3.1.2. The High Pricing Strategy of the Remanufacturer. Now, we pay attention to the case $p_{r}>\rho p_{n}$ and explore the high pricing strategy of the remanufacturer.

Proposition 2. Let

$$
\begin{aligned}
M A & =\max \left\{\bar{p}_{r, 1}^{(1)}, \bar{p}_{r, 2}^{(1)}, \bar{p}_{r}\right\}, \\
M I & =\min \left\{\bar{p}_{r, 1}^{(1)}, \bar{p}_{r, 2}^{(1)}, \bar{p}_{r}\right\} .
\end{aligned}
$$

If $M I \geq \rho p_{n}$, we use the high pricing strategy.

(i) When

$$
\begin{aligned}
& \frac{\gamma\left(1-p_{1}\right)}{\beta(1-M A)} \leq 2, \\
& \frac{\gamma\left(1-p_{1}\right)}{\beta(1-M I)} \geq 0,
\end{aligned}
$$

there is the optimal pricing strategy of the remanufacturer as follows:

if $b^{2}-4 a c \geq 0$,

$$
p_{r, i, G, 1}^{*}\left(p_{1}, p_{n}\right)=\bar{p}_{r, k}^{(1)} \text {, }
$$

s.t. $E\left[\Pi_{r}^{i, j}\left(\bar{p}_{r, k}^{(1)}\right)\right]=\max \left\{E\left[\Pi_{r}^{i, j}\left(\bar{p}_{r, l}^{(1)}\right)\right], l=1,2\right\}$.

Otherwise, $p_{r, i, G, 1}^{*}\left(p_{1}, p_{n}\right)=\rho p_{n}$.

(ii) When

$$
\frac{\gamma\left(1-p_{1}\right)}{\beta(1-M I)} \geq 2,
$$

the optimal solution is that

$$
p_{r, i, G, 2}^{*}\left(p_{1}, p_{n}\right)=\bar{p}_{r}=\frac{1+w_{i}}{2}
$$

The proof is seen in Appendix B.

3.2. The Model of the OEM. We think about the OEM's objective function stated by

$$
\begin{aligned}
& \max E\left[\Pi_{n}^{i j}\right] \\
& \quad=\max E\left[\left(\left(p_{1}-c_{i}\right) q_{1}-T_{i}\right)+\delta\left(\left(p_{n}-c_{i}\right) q_{n}^{j}\right)\right] .
\end{aligned}
$$


3.2.1. OEMs' Pricing Strategy Facing the Remanufacturer's Low Pricing Strategy. At first, we consider what response the OEM should have when the remanufacturer uses the low pricing strategy. The market demand of new products in the second period is

$$
q_{n}^{S}=(1-\beta) \Delta A\left(\frac{1-\rho-p_{n}+p_{r}}{1-\rho}\right) .
$$

At this time, one can get the following result.

Proposition 3. When the remanufacturer uses the low pricing strategy, the OEM's best reaction is as follows:

(i) When

$$
\begin{aligned}
f(\max ) & \leq 2, \\
f(\min ) & \geq 0, \\
p_{1, i, S, 1}^{*} & =\frac{1+c_{i}}{2}, \\
p_{n, i, S, 1}^{*} & =\frac{1}{2}\left(1-\rho+p_{r, S, 1}^{*}\left(p_{1, S, 1}^{*} p_{n, S, 1}^{*}\right)+c_{i}\right) .
\end{aligned}
$$

(ii) When

$$
\begin{aligned}
f(\min ) & \geq 2, \\
p_{1, i, S, 2}^{*} & =\frac{1+c_{i}}{2}, \\
p_{n, i, S, 2}^{*} & =\frac{1}{2}\left(1-\rho+p_{r, S, 2}^{*}\left(p_{1, S}^{*} p_{n, S, 2}^{*}\right)+c_{i}\right) .
\end{aligned}
$$

The proof is seen in Appendix C.

3.2.2. OEMs' Pricing Strategy Facing the Remanufacturer's High Pricing Strategy. Next, we think about what response the OEM should have when the remanufacturer uses the high pricing strategy. The market demand of new products in the second period is

$$
q_{n}^{G}=(1-\beta) \Delta A\left(1-p_{n}\right) .
$$

At this time, one can get the result as follows.

Proposition 4. When the remanufacturer uses the high pricing strategy, the OEM's best response function is as follows:

$$
\begin{aligned}
& p_{1, i, G}^{*}=\frac{1+c_{i}}{2}, \\
& p_{n, i, G}^{*}=\frac{1+c_{i}}{2} .
\end{aligned}
$$

The proof is displayed in Appendix D.

\section{The Pricing Strategies}

Though we employ the Stackelberg model in the second period in order to present the optimal solution, we are inspired by Deng's work to notice uncertainty of the market scale in the second period. In more detail, in the second period, the remanufacturer collects the end-life-cycle product produced by OEMs in the first period. We demonstrate that the OEM can observe the pricing strategy of the remanufacturer in the second period as the Stackelberg model believes. Relying on the information about the pricing strategy of the remanufacturer, OEMs can choose the most advantageous pricing strategy for their own. This interactively competitive relationship between OEMs and remanufacturers is a stable basis of the pricing strategies of OEMs and remanufacturers.

From remanufacturers' standpoint, according to the principle of maximizing the expected utility function, they will choose the optimal pricing strategies. Detailedly, the low pricing strategy can impel the remanufacturer to be prone to the benefit from the whole market including the primary and green markets while the high pricing strategy only makes the remanufacturer dominate the green market and obtain the profit from the green market. Therefore, if the low pricing strategy, through penetrating the whole market, can bring the remanufacturer more benefit than the high pricing strategy by which the remanufacturer only stands to gain from the green market, the remanufacturers will prefer the low pricing strategy to the high pricing strategy (Proposition 1). Otherwise, if the high pricing strategy brings more benefit to the remanufacturer than the low pricing strategy, the remanufacturer will choose the high pricing strategy rather than the low pricing strategy (Proposition 2).

From OEMs' standpoint, OEMs also make the optimal choice of their own pricing strategy to get maximal value of their expected utility according to the high and low pricing strategies of the remanufacturer. When the remanufacturer accepts the low pricing strategy, OEMs have to share the primal market with the remanufacture. When the remanufacturer chooses the high pricing strategy, OEMs can monopolize the primary market. Therefore, OEMs should differently react to the different pricing strategy of the remanufacturer. Particularly, if the remanufacturers choose the low strategy, OEMs will choose the pricing strategy of Proposition 3. Otherwise, when the remanufacturers use the high pricing strategy, OEMs will accept the pricing strategy of Proposition 2.

\section{The Numerical Analysis}

In this section, with a numerical method, we test the sensitivity of the optimal solutions to the different parameters in order to analyze influence of all kinds of paraments in the models on the pricing strategies. Let $c_{L}=0.4, C_{H}=0.2$, $W_{L}=0.3$, and $W_{H}=0.1$.

5.1. Testing the Sensitivity of the Optimal Solution to the Parameter $\rho$. Firstly, we research the sensitivity of the optimal pricing strategy to the parameter $\rho$. From Figures 1 and 2, we observe that $p_{1}, p_{n}$, and $p_{r}$ are equal to the same constant no matter whether there is low or high level of disassemblability, when remanufacturers choose the high pricing strategy. That 
is, this high pricing is independent of $\rho$. In the perspective of economics, $p_{1}$ is the price determined by OEMs in the first period. Since OEMs have to decide the price $p_{1}$ before the second period, the price $p_{1}$ is irrelevant to the restriction on the price of the remanufactured products in the second period. Meanwhile, the remanufacturers accept the high pricing strategy; hence, the remanufacturers only dominate the green market and the OEMs monopolize the primary market. Thus, at this time, the profit of remanufacturers reaches maximal value when remanufacturers choose the same price as OEMs (Proposition 2). In other words, the high price strategy's object is to get interest from the green market in which there are only green consumers not primary consumers. So the price which the primary consumers are willing to pay for the remanufactured product is not related to the high pricing strategy of remanufacturers.

When remanufacturers choose the low pricing strategy, $\rho$ has the same effect trend for strategies regardless of the different levels of disassemblability. $p_{1}$ is still a constant (Proposition 3), which the previously mentioned reason results in. $p_{r}$ increases at the same speed with the same level of disassemblability. It is valuable to state that on the different levels of disassemblability these slopes are different. As for the high disassemblability, when $\rho=0.28$ and $\rho=0.66$, $p_{r}$ has two leap growths and keeps the unchanged slope. From the economic point of view, when remanufacturers choose the low pricing strategy, they hope to penetrate to the whole market including the primary and green sections. In the primary market, the profit of a remanufactured product is closely related to the primary consumers' willingness to pay for the remanufactured product (Proposition 1). If primary consumers put the higher value on a remanufactured product, remanufacturers will sell their product at a higher price and obtain higher profit. Since the OEM has to share the primary market with the remanufacturer, $p_{n}$ is chosen based on $p_{r}$ (Proposition 3) and the large change of $p_{r}$ affects $p_{n}$. Hence, $p_{n}$ remain unchanged until $\rho=0.28$ and $\rho=0.66$. As for the low disassemblability, the similar case appears to be the high disassemblability.

Of course, we will focus on the impact of the different levels of disassemblability on the optimal pricing strategies. The different levels of disassemblability directly affect the cost $c_{i}$ of the OEM in the first period. In particular, the higher the level of disassemblability, the higher the cost $c_{i}$ in the first period. Then the higher cost leads to the higher price in the first period. As for the low pricing strategy of the remanufacture, the OEM will make the price in the first period $p_{1}=0.7$ for the high disassemblability while it will make the price $p_{1}=0.6$ for the low disassemblability. Moreover, the different levels of disassemblability also impact on the disassembling cost of the remanufacturer in the second period, when the remanufacturer accepts the low pricing strategy. Figures 1 and 2 describe that the impact of the level of disassemblability on the pricing strategies of the remanufacturer is mainly reflected in two aspects, the gradient of the optimal solution of the remanufacturer and the number of the thresholds. This gradient with the high disassemblability is bigger than one with the low disassemblability. There are two thresholds in the case of the high disassemblability,
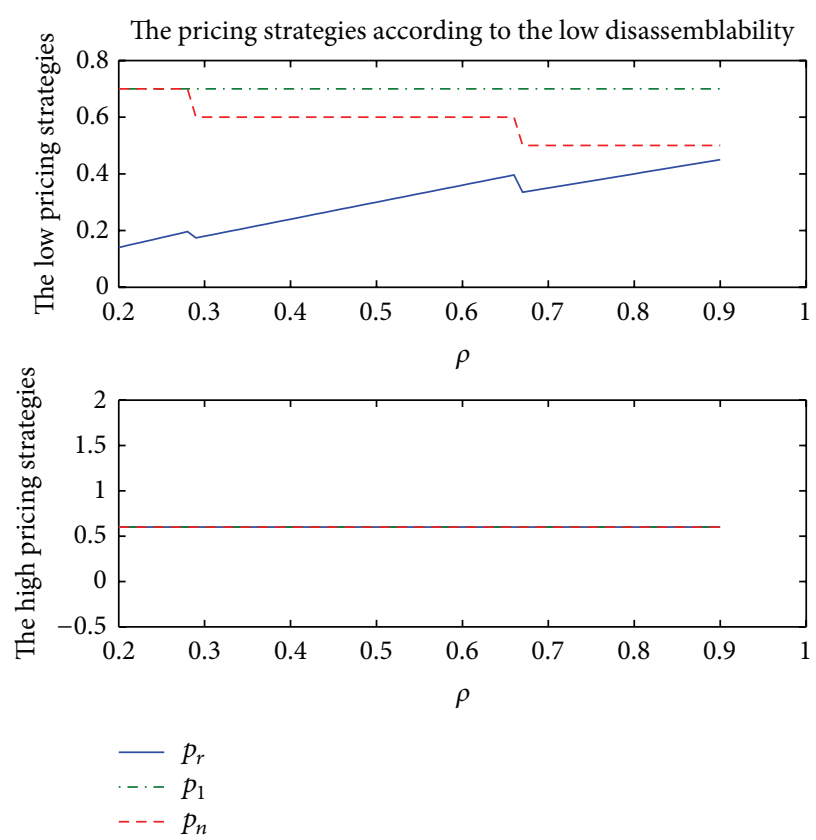

FIGURE 1: The pricing strategy according to the high disassemblability.
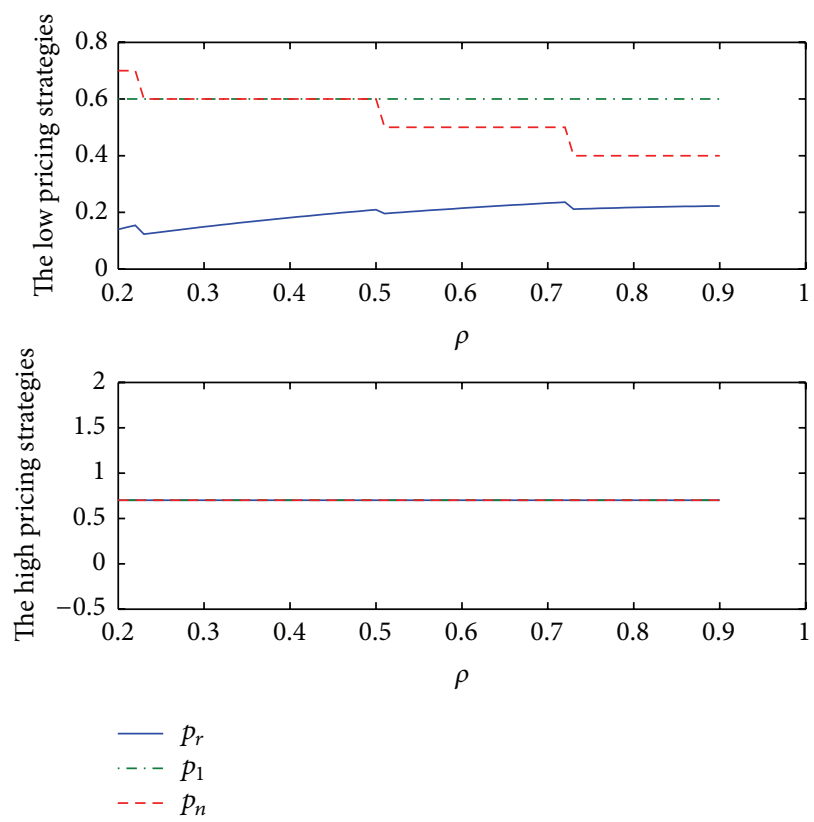

FIGURE 2: The pricing strategy according to the low disassemblability.

$\rho=0.28$ and $\rho=0.66$. At these two points, $p_{r}$ has two leap growths and keeps the unchanged slope. Accordingly, in the case of the low disassemblability, there are three thresholds, $\rho=0.23, \rho=0.5$, and $\rho=0.73$. Since the OEM shares the primary market with the remanufacturer, the optimal solution $p_{n}$ differs according to the difference of $p_{r}$.

5.2. Testing the Sensitivity of the Optimal Solution to the Parameter $\beta$. Next, we discuss the parameter $\beta$ 's effect on 

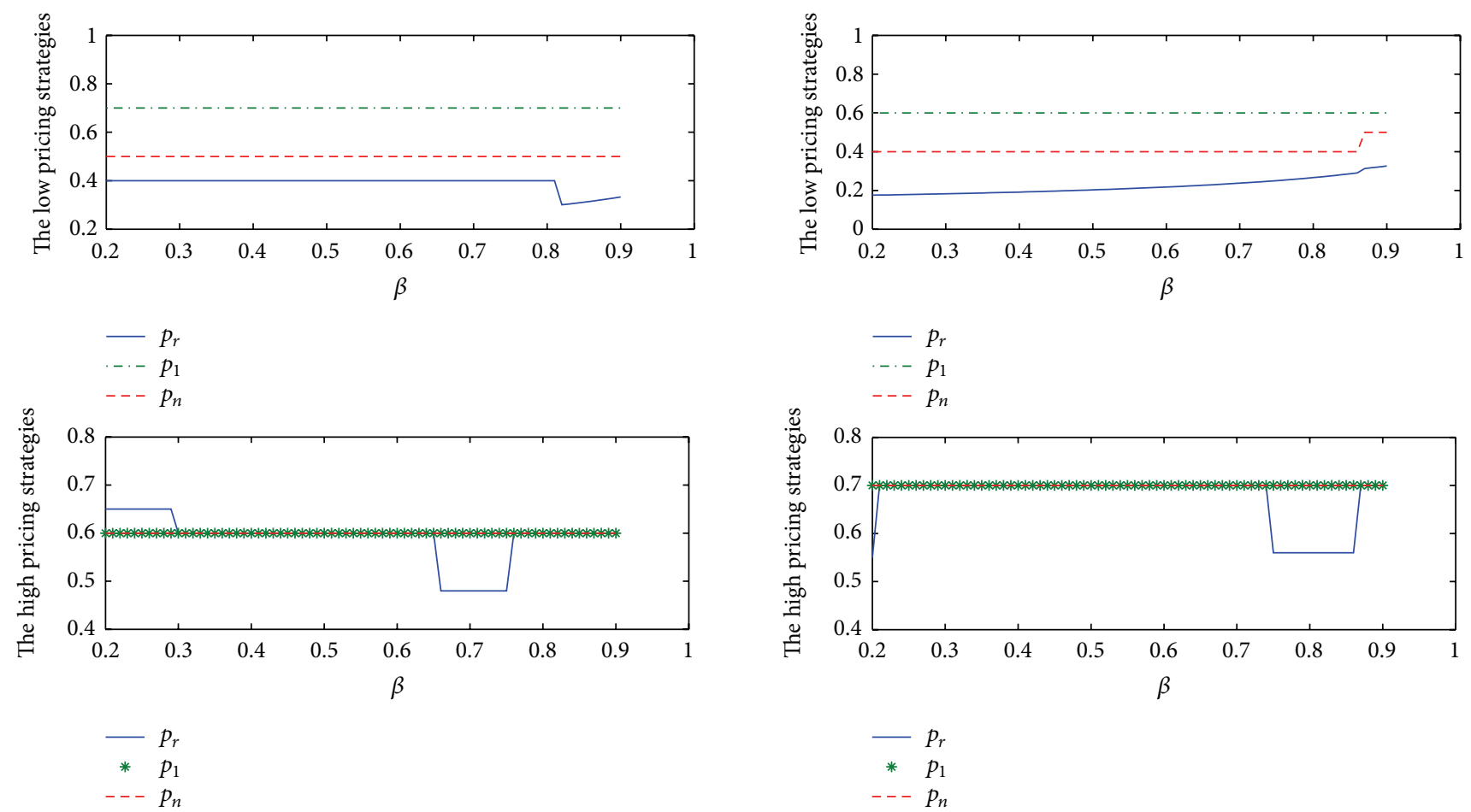

FIGURE 3: The pricing strategy according to the low disassemblability.

FIGURE 4: The pricing strategy according to the high disassemblability.

the pricing strategies. $p_{1}$ is two different constants in the high and low pricing strategies, respectively. From economic standpoint, because $p_{1}$ is the price of a new product in the first period and at this time there are only new products, the green and the primary consumers are indifferent. Therefore, $p_{1}$ is unrelated to the proportion of green consumers on the whole market, $\beta$.

$p_{n}$ almost keeps unchanged except that $\beta=0.86$ and remanufacturers choose the low strategy on the high level of disassemblability. Figures 3 and 4 present an obvious evidence that the OEM's pricing strategy in the second period $p_{n}$ is different due to the difference of the remanufacturer's pricing strategy. In more detail, on the low level of disassemblability (see Figure 3), when the remanufacturer accepts the low pricing strategy, the OEM's pricing strategy in the second period $p_{n}=0.5$, while when the remanufacturer chooses the high pricing strategy, the OEM's pricing strategy in the second period $p_{n}=0.6$. On the high level of disassemblability (see Figure 3), when the remanufacturer accepts the low pricing strategy, the OEM's pricing strategy in the second period $p_{n}=0.4$, while when the remanufacturer chooses the high pricing strategy, the OEM's pricing strategy in the second period $p_{n}=0.7$. From economic viewpoint, the remanufacturers prefer the low pricing strategy because they want to share the primary market with OEMs and get profit from the primary. So, it is inevitable to exit the pricing competition between the OEM and the remanufacture in the second period. Therefore, when remanufacturers choose low pricing strategy, the OEM has to accept the lower price strategy than when remanufacturers accept high pricing

strategy, in order to compete with the remanufacturer in the primary market.

On the low level of disassemblability, remanufacturers' low pricing strategy almost remains stable except $\beta=0.81$. And remanufacturers' low pricing strategy almost keeps steady except $\beta=0.29, \beta=0.64$, and $\beta=0.77$ (see Figure 3). On the high level of disassemblability, remanufacturers' high pricing strategy almost keeps steady except $\beta=0.21, \beta=$ 0.73 , and $\beta=0.81$ (see Figure 4 ). When remanufacturers accept the low strategy, their product's price increases with $\beta$ raise. Similar to the above, regardless of the different level of disassemblability, the remanufacturer always chooses the lower pricing strategy than the OEM to get benefit from the primary market. Namely, the price of the low pricing strategy of remanufacture $p_{r}$ is lower than the OEM's price $p_{n}$. When remanufacturers accept the high pricing strategy and only predominate in the green market, they will set a price which is as high as the OEM in order to gain the most profit from the green market.

Last but not least, the different levels of disassemblability impact on the pricing strategy of the remanufacturer and the OEM's pricing strategy. We first focus on the case of the low pricing strategy of the remanufacture. Because the high level of disassemblability can reduce the cost of disassembling used products, the remanufacturer determines the lower price strategy ( $p_{r}$ is less than 0.2 in Figure 4 ) compared to the low level of disassemblability $\left(p_{r}=0.4\right.$ in Figure 3$)$ in order to have an advantage over the OEM in the primary market. Meanwhile, for competing with the remanufacturer in the primary market, the OEMs have to reduce their price 
in the case of the high level of disassemblability $\left(p_{n}=0.4\right.$ in Figure 4). Then, we take the case of the high pricing strategy of the remanufacturer. Because the high level of disassemblability increases the cost of OEMs, the OEM determines the higher price in the first period $\left(p_{1}=0.7\right.$ in Figure 4) compared to the low level of disassemblability $\left(p_{1}=0.6\right.$ in Figure 3$)$. In the second period, remanufactures only dominate in the green market and OEMs monopolize the primary market. So, the OEMs need not to consider the competition with the remanufacturer in the primary market and can choose the higher price $\left(p_{n}=0.7\right.$ in Figure 4) compared to the low level of disassemblability $\left(p_{n}=0.6\right)$. At the same time, the remanufacturer can choose the same price as the OEM regardless the different levels of disassemblability $\left(p_{r}=p_{n}=0.6\right.$ in Figure 3 and $p_{r}=p_{n}=0.7$ in Figure 4).

\section{The Conclusion}

As mentioned earlier, our best endeavors and attempts are to safely come to meaningful conclusions in the theoretical and numerical areas.

Theoretically, through the mathematically sophisticated and complicated derivation of solution, we state the considerably surprising and subtle solution in explicit form. The shortcoming of the traditional Stackelberg model is that the market scale in the second period is supposed to be certain. The unrealistic assumption impedes the progress in the application and impact of Stackelberg model. Hence, our theoretical contribution is meaningful and significant.

In the numerical aspect, we not only tested the sensitivity of the optimal pricing strategies to the different parameters $\rho$ and $\beta$ in the numerical means but also analyze the influence of the different levels of disassemblability on the pricing strategies. The parameters $\rho$ and $\beta$ only impact on the pricing strategies in the second period regardless of the OEM or the remanufacturer, since these parameters are only related to the second period but do not associate with the first period. The parameter $\rho$ more obviously affects the low pricing strategy of the remanufacturer compared to the high one. The low pricing strategy will increase with $\rho$ increasing. In contrast to the parameter $\rho$, the parameter $\beta$ more evidently impacts on the high pricing strategy of the remanufacture compared to the low one. As a whole, there are some thresholds $(\beta=0.29$, $\beta=0.64$, and $\beta=0.77$ in Figure 3 and $\beta=0.21, \beta=0.73$, and $\beta=0.81$ in Figure 4 ) at which the pricing strategies have sudden changes and jump. On the other hand, the different level of disassemblability can increase the cost of the OEM and reduce the cost of disassembling used products, which result in the changes of the pricing strategies of OEMs and remanufactures. The concrete influence of disassemblability has been mentioned earlier.

To summarize, our main contribution in this paper is to achieve an explicitly optimal solution for the uncertain market size in the second period and to provide the theoretical background and framework for other related research. Furthermore, it is significant and meaningful that we test the sensitivity of optimal pricing to the different parameters by the numerical method, which helps us analyze the key elements impacting on the optimal solution.

\section{Further Research}

Although we have achieved notable and novel findings, this research is not perfect. In this paper, the alterable parameters in our problem are far more than the illustrated parameters $\rho$ and $\beta$ by us. Other parameters' variety, we believe, will impact the optimal solution. In later research, we will explore various cases in which other paraments, such as $w_{i}, c_{i}$, and $\gamma$, are variables. Moreover, we will incorporate adversarial risk analysis and prospect theory into the pricing strategies in order to make the research results be of more practical value. We may further undertake abundant game model in the problems about the pricing strategy and combine the previously mentioned subtle theories with practical methods into these problems about the pricing strategy.

\section{Appendix}

\section{A. The Proof of Proposition 1}

Proof. When $q_{r}^{S} \leq \gamma q_{1}$, we can get (please see [22])

$$
\begin{aligned}
\Pi_{r}^{i, j} & =\delta\left(p_{r}-w_{i}\right) q_{r}^{S}=\delta\left(p_{r}-w_{i}\right) \\
& \cdot\left((1-\beta) \Delta A \frac{\rho p_{n}-p_{r}}{\rho(1-\rho)}+\beta \Delta A\left(1-p_{r}\right)\right),
\end{aligned}
$$

while

$$
\Pi_{r}^{i, j}=\delta\left(p_{r}-w_{i}\right) \gamma q_{1}
$$

when $q_{r}^{S}>\gamma q_{1}$.

Let

$$
\begin{aligned}
q_{r}^{S} & =(1-\beta) \Delta A \frac{\rho p_{n}-p_{r}}{\rho(1-\rho)}+\beta \Delta A\left(1-p_{r}\right) \\
& =\gamma A\left(1-p_{1}\right)=\gamma q_{1},
\end{aligned}
$$

and then

$$
\Delta=\frac{\rho \gamma\left(1-p_{1}\right)}{\rho\left(\chi p_{n}+\beta\right)-p_{r}(\chi+\beta \rho)},
$$

where $\chi=(1-\beta) /(1-\rho)$.

To simply write, we set $f\left(p_{r}\right)=\rho \gamma\left(1-p_{1}\right) /\left(\rho\left(\chi p_{n}+\beta\right)-\right.$ $\left.p_{r}(\chi+\beta \rho)\right)$.

When $0 \leq \rho \gamma\left(1-p_{1}\right) /\left(\rho\left(\chi p_{n}+\beta\right)-p_{r}(\chi+\beta \rho)\right) \leq 2$,

$$
\begin{gathered}
E\left[\Pi_{r}^{i, j}\right]=E\left[\delta\left(p_{r}-w_{i}\right) q_{r}^{j}\right]=\int_{0}^{f\left(p_{r}\right)} \delta\left(p_{r}-w_{i}\right) \\
\cdot\left(\chi \Delta A \frac{\rho p_{n}-p_{r}}{\rho}+\beta \Delta A\left(1-p_{r}\right)\right) \frac{1}{2} d \Delta \\
+\int_{f\left(p_{r}\right)}^{2} \delta\left(p_{r}-w_{i}\right) \gamma q_{1} \frac{1}{2} d \Delta .
\end{gathered}
$$


We come back to (1). We only need to let

$$
\frac{\partial E\left[\Pi_{r}^{i, j}\right]}{\partial p_{r}}=0
$$

in order to get the maximal value of $E\left[\Pi_{r}^{i, j}\right]$.

Detailedly,

$$
\begin{aligned}
& \frac{\partial}{\partial p_{r}} E\left[\Pi_{r}^{i, j}\right]=\frac{\partial}{\partial p_{r}}\left[\frac{1}{2} \delta\left(p_{r}-w_{i}\right)\right. \\
& \left.\cdot\left(\chi A \frac{\rho p_{n}-p_{r}}{\rho}+\beta A\left(1-p_{r}\right)\right) \int_{0}^{f\left(p_{r}\right)} \Delta d \Delta\right] \\
& +\frac{\partial}{\partial p_{r}}\left[\frac{1}{2} \delta\left(p_{r}-w_{i}\right) \gamma q_{1} \int_{f\left(p_{r}\right)}^{2} d \Delta\right]=\frac{\partial}{\partial p_{r}}\left[\frac{1}{2}\right. \\
& \cdot \delta\left(p_{r}-w_{i}\right)\left(\chi A \frac{\rho p_{n}-p_{r}}{\rho}+\beta A\left(1-p_{r}\right)\right) \\
& \left.\cdot\left(\frac{1}{2} f^{2}\left(p_{r}\right)-0\right)\right]+\frac{\partial}{\partial p_{r}}\left[\frac{1}{2} \delta\left(p_{r}-w_{i}\right)\right. \\
& \left.\cdot \gamma q_{1}\left(2-f\left(p_{r}\right)\right)\right] .
\end{aligned}
$$

Simply write $B=\chi p_{n}+\beta, C=-\chi / \rho-\beta, D=\rho \gamma\left(1-p_{1}\right)$, $E=\rho\left(\chi p_{n}+\beta\right)$, and $F=-(\chi+\beta \rho)$. Consider

$$
\begin{aligned}
\frac{\partial}{\partial p_{r}} E\left[\Pi_{r}^{i, j}\right] & \\
= & \frac{1}{4} \delta A \frac{\partial}{\partial p_{r}}\left[\left(p_{r}-w_{i}\right)\left(B+C p_{r}\right) f^{2}\left(p_{r}\right)\right] \\
& +\frac{1}{2} \delta \gamma A\left(1-p_{1}\right) \frac{\partial}{\partial p_{r}}\left[\left(p_{r}-w_{i}\right)\left(2-f\left(p_{r}\right)\right)\right] \\
= & 0 .
\end{aligned}
$$

That is,

$$
\begin{aligned}
& \frac{\partial}{\partial p_{r}}\left[\left(p_{r}-w_{i}\right)\left(B+C p_{r}\right) f^{2}\left(p_{r}\right)\right] \\
& \quad+2 \gamma\left(1-p_{1}\right) \frac{\partial}{\partial p_{r}}\left[\left(p_{r}-w_{i}\right)\left(2-f\left(p_{r}\right)\right)\right]=0 \\
& \frac{\partial}{\partial p_{r}}\left[\left(p_{r}-w_{i}\right)\left(B+C p_{r}\right) f^{2}\left(p_{r}\right)\right] \\
& \quad=\left(B+2 C p_{r}-C w_{i}\right)\left(\frac{D}{E+F p_{r}}\right)^{2} \\
& \quad-2\left(p_{r}-w_{i}\right)\left(B+c p_{r}\right) \frac{D}{E+F p_{r}} \frac{D F}{\left(E+F p_{r}\right)^{2}} .
\end{aligned}
$$

Meanwhile,

$$
\begin{aligned}
2 \gamma & \left(1-p_{1}\right) \frac{\partial}{\partial p_{r}}\left[\left(p_{r}-w_{i}\right)\left(2-f\left(p_{r}\right)\right)\right] \\
& =2 \gamma\left(1-p_{1}\right) \\
& \cdot\left(2-f\left(p_{r}\right)-p_{r} f^{\prime}\left(p_{r}\right)+w_{i} f^{\prime}\left(p_{r}\right)\right) \\
& =2 \gamma\left(1-p_{1}\right) \\
& \cdot\left(2-\frac{D}{E+F p_{r}}+\left(w_{i}-p_{r}\right) \frac{-D F}{\left(E+F p_{r}\right)^{2}}\right) .
\end{aligned}
$$

Applying (A.10) and (A.11) into (A.9), we can get

$$
\begin{aligned}
& D^{2}\left(B+2 C p_{r}-C w_{i}\right)\left(E+F p_{r}\right)-2\left(p_{r}-w_{i}\right)(B \\
& \left.\quad+c p_{r}\right) D^{2} F+2 \gamma\left(1-p_{1}\right)\left(2\left(E-F p_{r}\right)^{3}\right. \\
& \left.\quad-D\left(E+F p_{r}\right)^{2}-D F\left(w_{i}-p_{r}\right)\left(E+F p_{r}\right)\right)=0 .
\end{aligned}
$$

That is,

$$
G p_{r}^{3}+H p_{r}^{2}+I p_{r}+J=0
$$

where

$$
\begin{aligned}
G= & 4 \gamma\left(1-p_{1}\right) F^{3}, \\
H= & 6 \gamma\left(1-p_{1}\right) E F, \\
I= & 2 D^{2} C E-D^{2} F\left(B-C w_{i}\right) \\
& +1 \gamma\left(1-p_{1}\right)\left(6 E^{2} F-D E F-D F^{2} w_{i}\right), \\
J= & D^{2} E\left(B-C w_{i}\right)+2 D^{2} F w_{i} B \\
& +2 \gamma\left(1-p_{1}\right)\left(2 E^{3}-D E^{2}-D w_{i} F E\right) .
\end{aligned}
$$

With Shengjin's formulas, we set $L=H^{2}-3 G I, M=H I-9 G J$, and $N=I^{2}-3 H J$.

When $L=M, p_{r}=-H / G<0$, so the optimal solution $p_{r}^{*}=\rho p_{n}$.

When $M^{2}-4 L N>0$,

$$
r=-\frac{H+Y_{1}^{1 / 3}+Y_{2}^{1 / 3}}{3 G},
$$

where

$$
\begin{aligned}
& Y_{1}=L H+\frac{3 G\left(-M+\left(M^{2}-4 L N\right)^{1 / 2}\right)}{2}, \\
& Y_{2}=L H+\frac{3 G\left(-M-\left(M^{2}-4 L N\right)^{1 / 2}\right)}{2} .
\end{aligned}
$$

We can get the remanufacturer's best response function described by

$$
\begin{aligned}
& p_{r}^{(1)} \\
& = \begin{cases}\rho p_{n} & \text { if } r \leq w_{L} \text { or } r \geq \rho p_{n}, \\
\max \left\{E\left[\Pi_{r}^{i, j}(r), \Pi_{r}^{i, j}\left(\rho p_{n}\right)\right]\right\} & \text { otherwise, }\end{cases} \\
p_{r}^{*} & =p_{r}^{(1)} .
\end{aligned}
$$


When $M^{2}-4 L N=0$,

$$
\begin{aligned}
& p_{r, 1}^{(2)}=-\frac{H}{G}+K, \\
& p_{r, 2}^{(2)}=-\frac{K}{2},
\end{aligned}
$$

where $K=M / L(L \neq 0)$. Let $\Omega_{1}=\left\{p_{r, l}^{(2)}: w_{L}<p_{r, l}^{(2)}<\rho p_{n}, l=\right.$ $1,2\}$. The optimal pricing strategy is written as

$$
\begin{aligned}
p_{r}^{*} & =p_{r}^{(2)} \\
& =\underset{p_{r, l}^{(2)}, \rho p_{n}}{\arg \max }\left\{E\left[\Pi_{r}^{i, j}\left(p_{r, l}^{(2)}\right)\right], E\left[\Pi_{r}^{i, j}\left(\rho p_{n}\right)\right], p_{r, l}^{(2)}\right. \\
& \left.\in \Omega_{1}\right\} .
\end{aligned}
$$

When $M^{2}-4 L N<0$,

$$
\begin{aligned}
& p_{r, 1}^{(3)}=\frac{-H+2 L^{1 / 2} \cos (\phi / 3)}{3 G}, \\
& p_{r, 2}^{(3)}=\frac{-H+L^{1 / 2}(\cos (\phi / 3)+\sqrt{3} \sin (\phi / 3))}{3 G} \\
& p_{r, 3}^{(3)}=\frac{-H+L^{1 / 2}(\cos (\phi / 3)-\sqrt{3} \sin (\phi / 3))}{3 G},
\end{aligned}
$$

where $\phi=\arccos T, T=(2 L H-3 G M) / 2 L^{1 / 3}$, and $-1<T<$ 1. Let $\Omega_{2}=\left\{p_{r, l}^{(3)}: w_{L}<p_{r, l}^{(2)}<n p_{n}, l=1,2,3\right\}$.

The remanufacturer's best response function is described as

$$
\begin{aligned}
p_{r}^{*} & =p_{r}^{(3)} \\
& =\underset{p_{r, l}^{(3)}, \rho p_{n}}{\arg \max }\left\{E\left[\Pi_{r}^{i, j}\left(p_{r, l}^{(3)}\right)\right], E\left[\Pi_{r}^{i, j}\left(\rho p_{n}\right)\right], p_{r, l}^{(3)}\right. \\
& \left.\in \Omega_{2}\right\} .
\end{aligned}
$$

$$
\text { When } \rho \gamma\left(1-p_{1}\right) /\left(\rho\left(\chi p_{n}+\beta\right)-p_{r}(\chi+\beta \rho)\right)>2 \text {, }
$$

$$
\begin{gathered}
E\left[\Pi_{r}^{i, j}\right]=E\left[\delta\left(p_{r}-w_{i}\right) q_{r}^{j}\right]=\int_{0}^{2} \delta\left(p_{r}-w_{i}\right) \\
\cdot\left((1-\beta) \Delta A \frac{\rho p_{n}-p_{r}}{\rho(1-\rho)}+\beta \Delta A\left(1-p_{r}\right)\right) \frac{1}{2} d \Delta,
\end{gathered}
$$

$$
\begin{aligned}
& \frac{\partial}{\partial p_{r}} E\left[\Pi_{r}^{i, j}\right]=\frac{\partial}{\partial p_{r}}\left[\int_{0}^{2} \delta\left(p_{r}-w_{i}\right)\right. \\
& \left.\cdot\left(\chi \Delta A \frac{\rho p_{n}-p_{r}}{\rho}+\beta \Delta A\left(1-p_{r}\right)\right) \frac{1}{2} d \Delta\right] \\
& \quad=\frac{\partial}{\partial p_{r}}\left[\frac { 1 } { 2 } A \delta ( p _ { r } - w _ { i } ) \left(\chi \frac{\rho p_{n}-p_{r}}{\rho}\right.\right. \\
& \left.\left.+\beta\left(1-p_{r}\right)\right) \int_{0}^{2} \Delta d \Delta\right]=\frac{\partial}{\partial p_{r}}\left[\frac{1}{2} \delta A\left(p_{r}-w_{i}\right)\right. \\
& \left.\cdot\left(\chi \frac{\rho p_{n}-p_{r}}{\rho}+\beta\left(1-p_{r}\right)\right) 4\right]=2 \delta A \frac{\partial}{\partial p_{r}}\left[\left(p_{r}\right.\right. \\
& \left.\left.\quad-w_{i}\right)\left(B+C p_{r}\right)\right]=2 C p_{r}+B-w_{i} C .
\end{aligned}
$$

Let $\left(\partial / \partial p_{r}\right) E\left[\Pi_{r}^{i, j}\right]=0$; then the best choice of remanufacturer's pricing strategy is

$$
p_{r}^{*}=p_{r}^{(4)}=\frac{w_{i} C-B}{2 C}=\frac{1}{2}\left(\frac{\rho\left(\beta+\chi p_{n}\right)}{\beta \rho+\chi}+w_{i}\right) .
$$

\section{B. The Proof of Proposition 2}

Proof. When $q_{r}^{G} \leq \gamma q_{1}$, we can get

$$
\Pi_{r}^{i, j}=\delta\left(p_{r}-w_{i}\right) q_{r}^{S}=\delta\left(p_{r}-w_{i}\right) \beta \Delta A\left(1-p_{r}\right),
$$

as well as

$$
\Pi_{r}^{i, j}=\delta\left(p_{r}-w_{i}\right) \gamma q_{1}
$$

when $q_{r}^{G}>\gamma q_{1}$.

Let

$$
q_{r}^{G}=\beta \Delta A\left(1-p_{r}\right)=\gamma A\left(1-p_{1}\right)=\gamma q_{1},
$$

and then

$$
\Delta=\frac{\gamma\left(1-p_{1}\right)}{\beta\left(1-p_{r}\right)} .
$$

When $0 \leq \gamma\left(1-p_{1}\right) / \beta\left(1-p_{r}\right) \leq 2$,

$$
\begin{aligned}
E[ & \left.\Pi_{r}^{i, j}\right]=E\left[\delta\left(p_{r}-w_{i}\right) q_{r}^{j}\right] \\
& =\int_{0}^{\gamma\left(1-p_{1}\right) / \beta\left(1-p_{r}\right)} \delta\left(p_{r}-w_{i}\right) \beta \Delta A\left(1-p_{r}\right) \frac{1}{2} d \Delta
\end{aligned}
$$$$
+\int_{\gamma\left(1-p_{1}\right) / \beta\left(1-p_{r}\right)}^{2} \delta\left(p_{r}-w_{i}\right) \gamma q_{1} \frac{1}{2} d \Delta
$$

$$
\begin{aligned}
= & \frac{1}{2} \delta\left(p_{r}-w_{1}\right) \beta A\left(1-p_{r}\right) \int_{0}^{\gamma\left(1-p_{1}\right) / \beta\left(1-p_{r}\right)} \Delta d \Delta \\
& +\frac{1}{2} A\left(1-p_{1}\right) \gamma \delta\left(p_{r}-w_{i}\right) \int_{\gamma\left(1-p_{1}\right) / \beta\left(1-p_{r}\right)}^{2} d \Delta .
\end{aligned}
$$


It is easy to see that we only need to let

$$
\frac{\partial E\left[\Pi_{r}^{i, j}\right]}{\partial p_{r}}=0
$$

to achieve the optimal solution of $E\left[\Pi_{r}^{i, j}\right]$.

It is described in detail that

$$
\begin{aligned}
& \frac{\partial}{\partial p_{r}} E\left[\Pi_{r}^{i, j}\right]=\frac{\partial}{\partial p_{r}}\left[\frac{1}{2} \delta\left(p_{r}-w_{1}\right) \beta A\left(1-p_{r}\right)\right. \\
& \left.\cdot \frac{1}{2}\left(\frac{\gamma\left(1-p_{1}\right)}{\beta\left(1-p_{r}\right)}\right)^{2}\right]+\frac{\partial}{\partial p_{r}}\left[\frac{1}{2} A\left(1-p_{1}\right)\right. \\
& \left.\cdot \gamma \delta\left(p_{r}-w_{i}\right)\left(2-\frac{\gamma\left(1-p_{1}\right)}{\beta\left(1-p_{r}\right)}\right)\right]=\frac{1}{4} \\
& \cdot \frac{\delta A \gamma(1-p-1)^{2}}{\beta} \frac{\partial}{\partial p_{r}}\left(\frac{p_{r}-w_{i}}{1-p_{r}}\right)+\frac{1}{2} A\left(1-p_{1}\right) \\
& \cdot \gamma \delta \frac{\partial}{\partial p_{r}}\left[\left(p_{r}-w_{i}\right)\left(2-\frac{\gamma\left(1-p_{1}\right)}{\beta\left(1-p_{r}\right)}\right)\right]=0 .
\end{aligned}
$$

It is simply written as

$$
\begin{aligned}
& \frac{\partial}{\partial p_{r}}\left(\frac{p_{r}-w_{i}}{1-p_{r}}\right) \\
& \quad+2 \beta \frac{\partial}{\partial p_{r}}\left[\left(p_{r}-w_{i}\right)\left(2-\frac{\gamma\left(1-p_{1}\right)}{\beta\left(1-p_{r}\right)}\right)\right]=0 .
\end{aligned}
$$

So

$$
4 \beta p_{r}^{2}-8 \beta p_{r}+\left[1-2 \gamma\left(1-p_{1}\right)\right]\left(1-w_{i}\right)+4 \beta=0 .
$$

Set $a=4 \beta, b=-8 \beta$, and $c=\left[1-2 \gamma\left(1-p_{1}\right)\right]\left(1-w_{i}\right)+4 \beta$. When $b^{2}-4 a c \geq 0$,

$$
\begin{aligned}
& \bar{p}_{r, 1}^{(1)}=\frac{-b+\sqrt{b^{2}-4 a c}}{2 a}, \\
& \bar{p}_{r, 2}^{(1)}=\frac{-b-\sqrt{b^{2}-4 a c}}{2 a} .
\end{aligned}
$$

At present, the optimal pricing strategy is as follows:

$$
\begin{aligned}
& p_{r}^{*}=\bar{p}_{r, k}^{(1)}, \\
& \quad \text { if } E\left[\Pi_{r}^{i, j}\left(\bar{p}_{r, k}^{(1)}\right)\right]=\max \left\{E\left[\Pi_{r}^{i, j}\left(\bar{p}_{r, l}^{(1)}\right)\right], l=1,2\right\} .
\end{aligned}
$$

When $b^{2}-4 a c<0$, there is no solution for the problem.

When $\gamma\left(1-p_{1}\right) / \beta\left(1-p_{r}\right)>2$,

$$
\begin{aligned}
E\left[\Pi_{r}^{i, j}\right] & =E\left[\delta\left(p_{r}-w_{i}\right) q_{r}^{j}\right] \\
& =\int_{0}^{2} \delta\left(p_{r}-w_{i}\right) \beta \Delta A\left(1-p_{r}\right) \frac{1}{2} d \Delta \\
& =\frac{1}{2} \delta\left(p_{r}-w_{i}\right) \beta A\left(1-p_{r}\right) \int_{0}^{2} \Delta d \Delta \\
& =\delta\left(p_{r}-w_{i}\right) \beta A\left(1-p_{r}\right) .
\end{aligned}
$$

It is easy to see that we only need to let

$$
\frac{\partial E\left[\Pi_{r}^{i, j}\right]}{\partial p_{r}}=\delta \beta A\left(1-2 p_{r}+w_{i}\right)=0
$$

to achieve the optimal solution of $E\left[\Pi_{r}^{i, j}\right]$.

That is to say, the optimal solution is as follows:

$$
p_{r}^{*}=\bar{p}_{r}=\frac{1+w_{i}}{2}
$$

\section{The Proof of Proposition 3}

Proof. The market demand of new products in the second period is

$$
q_{n}^{S}=(1-\beta) \Delta A\left(\frac{1-\rho-p_{n}+p_{r}}{1-\rho}\right) .
$$

Therefore,

$$
\begin{aligned}
E[ & \left.\Pi_{n}^{i S}\right]=E\left[\left(\left(p_{1}-c_{i}\right) q_{1}-T_{i}\right)+\delta\left(\left(p_{n}-c_{i}\right) q_{n}^{S}\right)\right] \\
& =E\left[\left(\left(p_{1}-c_{i}\right) q_{1}-T_{i}\right)+\delta\left(p_{n}-c_{i}\right)(1-\beta)\right. \\
& \left.\cdot \Delta A\left(\frac{1-\rho-p_{n}+p_{r}}{1-\rho}\right)\right] \\
& =\int_{0}^{2}\left(\left(p_{1}-c_{i}\right) q_{1}-T_{i}\right)+\delta\left(p_{n}-c_{i}\right)(1-\beta) \\
& \cdot \Delta A\left(\frac{1-\rho-p_{n}+p_{r}}{1-\rho}\right) d \Delta \\
& =2\left(\left(\left(p_{1}-c_{i}\right) q_{1}-T_{i}\right)+\delta\left(p_{n}-c_{i}\right)(1-\beta)\right. \\
& \left.\cdot A\left(\frac{1-\rho-p_{n}+p_{r}}{1-\rho}\right)\right) .
\end{aligned}
$$

Let

$$
\begin{aligned}
& \frac{\partial}{\partial p_{1}} E\left[\Pi_{n}^{i S}\right]=2\left(\left(\left(p_{1}-c_{i}\right) q_{1}-T_{i}\right)\right. \\
& \left.\quad+\left(p_{n}-c_{i}\right)(1-\beta) A\left(\frac{1-\rho-p_{n}+p_{r}}{1-\rho}\right)\right)=0 \\
& \frac{\partial}{\partial p_{n}} E\left[\Pi_{n}^{i S}\right]=2\left(\left(\left(p_{1}-c_{i}\right) q_{1}-T_{i}\right)\right. \\
& \left.\quad+\left(p_{n}-c_{i}\right)(1-\beta) A\left(\frac{1-\rho-p_{n}+p_{r}}{1-\rho}\right)\right)=0 .
\end{aligned}
$$

Then,

$$
\begin{aligned}
& p_{1}^{*}=\frac{1+c_{i}}{2} \\
& p_{n}^{*}=\frac{1}{2}\left(1-\rho+p_{r}+c_{i}\right) .
\end{aligned}
$$




\section{The Proof of the Proposition 4}

Proof. The market demand of new products in the second period is

$$
q_{n}^{G}=(1-\beta) \Delta A\left(1-p_{n}\right)
$$

Therefore,

$$
\begin{aligned}
E[ & \left.\Pi_{n}^{i G}\right]=E\left[\left(\left(p_{1}-c_{i}\right) q_{1}-T_{i}\right)+\delta\left(\left(p_{n}-c_{i}\right) q_{n}^{G}\right)\right] \\
& =E\left[\left(\left(p_{1}-c_{i}\right) q_{1}-T_{i}\right)\right. \\
& \left.+\delta\left(p_{n}-c_{i}\right)(1-\beta) \Delta A\left(1-p_{n}\right)\right] \\
& =\int_{0}^{2}\left(\left(p_{1}-c_{i}\right) q_{1}-T_{i}\right) \\
& +\delta\left(p_{n}-c_{i}\right)(1-\beta) \Delta A\left(1-p_{n}\right) d \Delta \\
& =2\left(\left(\left(p_{1}-c_{i}\right) q_{1}-T_{i}\right)\right. \\
& \left.+\delta\left(p_{n}-c_{i}\right)(1-\beta) A\left(1-p_{n}\right)\right)
\end{aligned}
$$

Let

$$
\begin{aligned}
& \frac{\partial}{\partial p_{1}} E\left[\Pi_{n}^{i G}\right]=0 \\
& \frac{\partial}{\partial p_{n}} E\left[\Pi_{n}^{i G}\right]=0 .
\end{aligned}
$$

Then,

$$
\begin{aligned}
& p_{1}^{*}=\frac{1+c_{i}}{2}, \\
& p_{n}^{*}=\frac{1}{2}\left(1+c_{i}\right) .
\end{aligned}
$$

\section{Competing Interests}

The authors declare that they have no competing interests.

\section{Acknowledgments}

The paper is supported by National Natural Science Foundation of China (no. 71201051), Young Talents Training Plan of Hunan Normal University (no. 2014YX04), and Philosophical and Social Science Fund of Hunan (no. 14YBA264).

\section{References}

[1] A. M. A. El Saadany and M. Y. Jaber, "A production/remanufacturing inventory model with price and quality dependant return rate," Computers and Industrial Engineering, vol. 58, no. 3, pp. 352-362, 2010.

[2] N. Varel, "Lifecycle analysis and costing in an environmentally conscious manufacturing environment," in Proceedings of the APICS Remanufacturing Symposium, pp. 44-47, Dayton, Ohio, USA, May 1996.
[3] G. P. Hammond, "Science, sustainability and the establishment in a technological age," Interdisciplinary Science Reviews, vol. 29, no. 2, pp. 193-208, 2004.

[4] W. L. Ijomah, C. A. McMahon, G. P. Hammond, and S. T. Newman, "Development of design for remanufacturing guidelines to support sustainable manufacturing," Robotics and ComputerIntegrated Manufacturing, vol. 23, no. 6, pp. 712-719, 2007.

[5] V. D. Guide Jr., "Remanufacturing production planning and control: US industry best practice and research issues," in Proceedings of the 2nd International Working Paper on Re-Use, pp. 115-128, Eindhoven, Netherlands, 1999.

[6] A. Hormozi, "Remanufacturing and its consumer, economic and environmental benefits," in Proceedings of the APEX Remanufacturing Symposium, pp. 5-7, May 1996.

[7] J. Östlin, E. Sundin, and M. Björkman, "Product life-cycle implications for remanufacturing strategies," Journal of Cleaner Production, vol. 17, no. 11, pp. 999-1009, 2009.

[8] R. T. Lund, "Remanufacturing: the experience of the USA and implications for the developing contries," World Bank Technical paper 3, 1984.

[9] R. T. Lund, Remanufacturing Industry: Hidden Giant, Boston University, Boston, Mass, USA, 1996.

[10] R. Giuntini and K. Gaudette, "Remanufacturing: the next great opportunity for boosting US productivity," Business Horizons, vol. 46, no. 6, pp. 41-48, 2003.

[11] S. Webster and S. Mitra, "Competitive strategy in remanufacturing and the impact of take-back laws," Journal of Operations Management, vol. 25, no. 6, pp. 1123-1140, 2007.

[12] Global Industry Analysts, Automotive Remanufacturing: Market Research Report, Market Publishers, 2010, http://marketpublishers.com/.

[13] P. Majumder and H. Groenevelt, "Competition in remanufacturing," Production and Operations Management, vol. 10, no. 2, pp. 125-141, 2001.

[14] R. C. Savaskan, S. Bhattacharya, and L. N. Van Wassenhove, "Closed-loop supply chain models with product remanufacturing," Management Science, vol. 50, no. 2, pp. 239-252, 2004.

[15] M. Y. Jaber and A. M. A. El Saadany, "The production, remanufacture and waste disposal model with lost sales," International Journal of Production Economics, vol. 120, no. 1, pp. 115-124, 2009.

[16] V. Agrawal, A. Atasu, and K. Ittersum, "The effect of remanufacturing on the perceived value of new products," Working Paper, 2010.

[17] A. M. King, S. C. Burgess, W. Ijomah, and C. A. McMahon, "Reducing waste: repair, recondition, remanufacture or recycle?" Sustainable Development, vol. 14, no. 4, pp. 257-267, 2006.

[18] H. Yuksel, "Design of automobile engines for remanufacture with quality function deployment," International Journal of Sustainable Engineering, vol. 3, no. 3, pp. 170-180, 2010.

[19] G. Ferrer and J. M. Swaminathan, "Managing new and remanufactured products," Management Science, vol. 52, no. 1, pp. 1526, 2006.

[20] G. Ferrer and J. M. Swaminathan, "Managing new and differentiated remanufactured products," European Journal of Operational Research, vol. 203, no. 2, pp. 370-379, 2010.

[21] H. Cheng, "OEM product design in a price competition with remanufactured product," Omega, vol. 41, no. 2, pp. 287-298, 2013.

[22] C.-H. Wu, "Product-design and pricing strategies with remanufacturing," European Journal of Operational Research, vol. 222, no. 2, pp. 204-215, 2012. 
[23] C.-H. Wu, "Price and service competition between new and remanufactured products in a two-echelon supply chain," International Journal of Production Economics, vol. 140, no. 1, pp. 496-507, 2012.

[24] S. Mitra, "Revenue management for remanufactured products," Omega, vol. 35, no. 5, pp. 553-562, 2007.

[25] L. Deng, W. Li, and Z. Liu, "Different subsidies' impact on equilibrium decision-making of closed-loop supply chain," Journal of Industrial Engineering and Management, vol. 7, no. 5, pp. 1061-1075, 2014.

[26] L. Deng and B. Ma, "Application of adversarial risk analysis model in pricing strategies with remanufacturing," Journal of Industrial Engineering and Management, vol. 8, no. 1, pp. 1-20, 2015.

[27] A. Atasu, M. Sarvary, and L. N. van Wassenhove, "Remanufacturing as a marketing strategy," Management Science, vol. 54, no. 10, pp. 1731-1746, 2008.

[28] A. Atasu, V. D. R. Guide, and L. N. Van Wassenhove, "Product reuse economics in closed-loop supply chain research," Production and Operations Management, vol. 17, no. 5, pp. 483-496, 2008. 


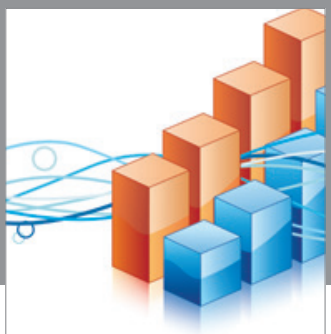

Advances in

Operations Research

vatem alat4

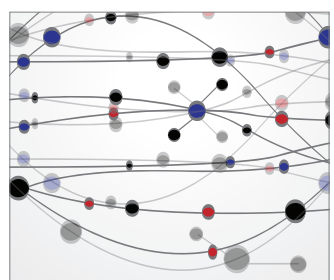

\section{The Scientific} World Journal
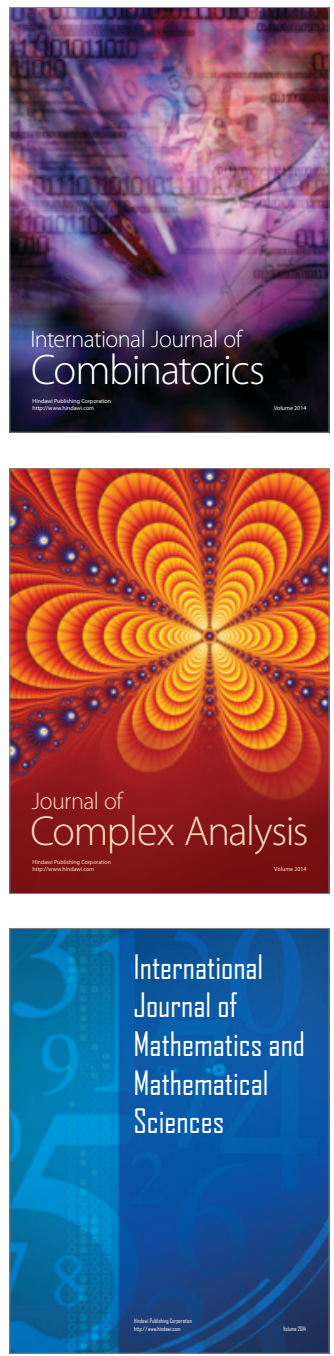
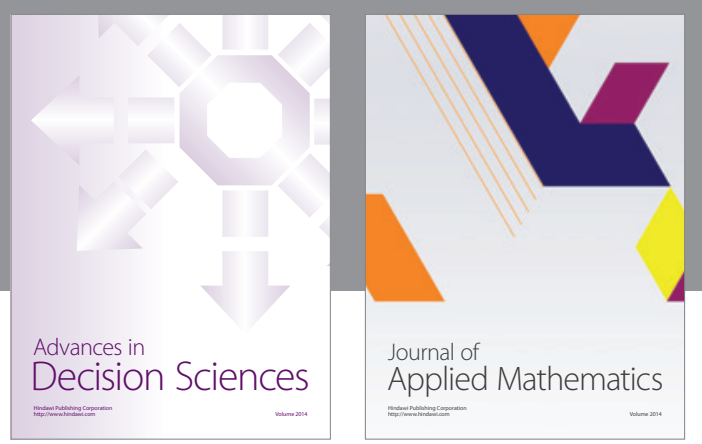

Algebra

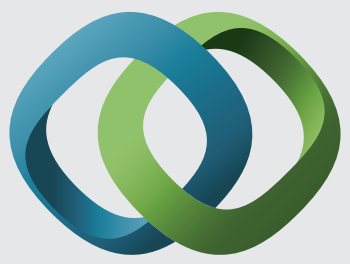

\section{Hindawi}

Submit your manuscripts at

http://www.hindawi.com
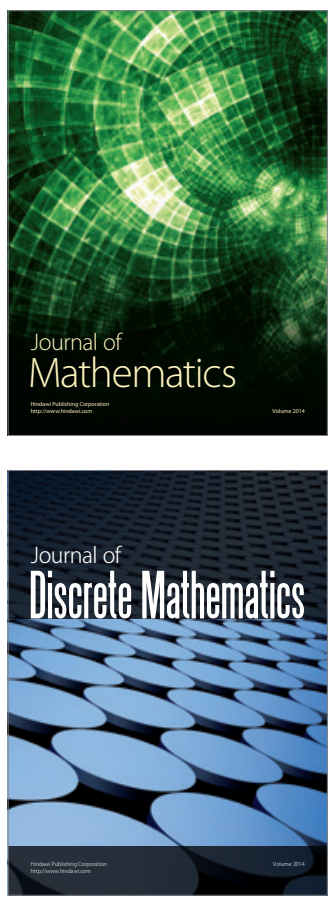

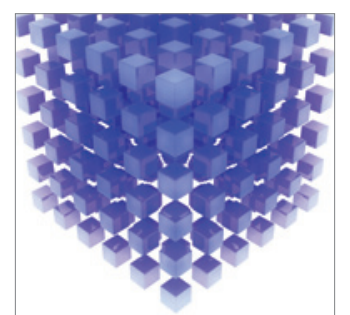

Mathematical Problems in Engineering
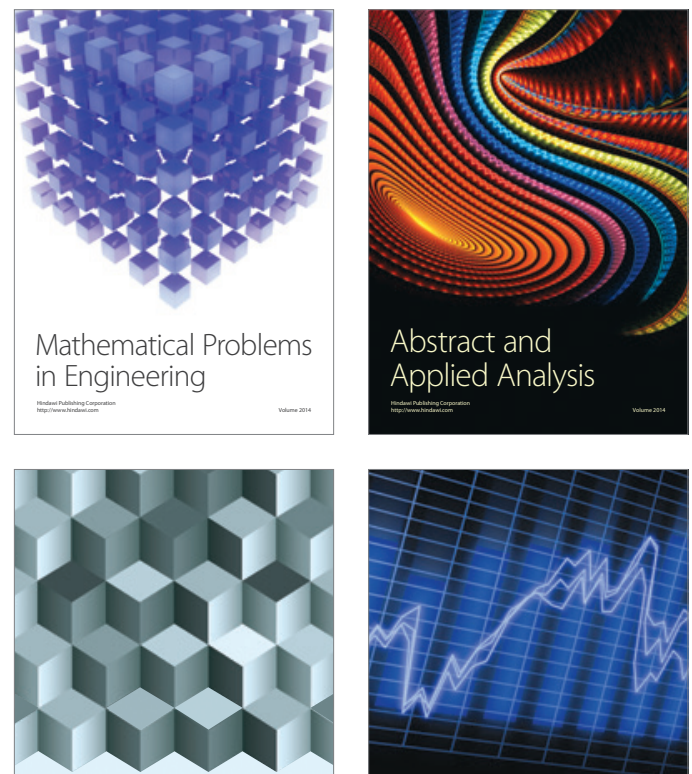

Journal of

Function Spaces

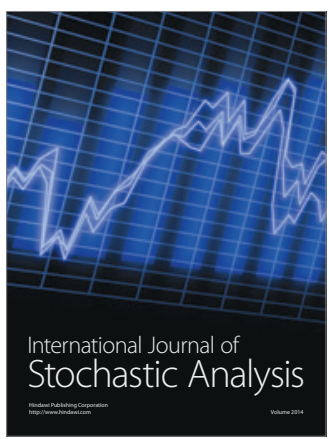

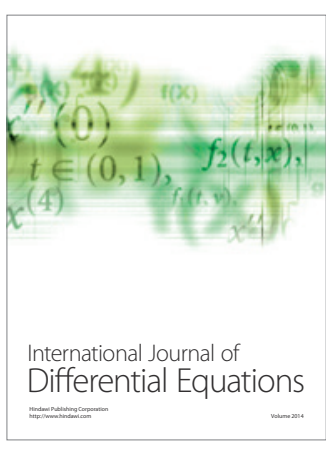
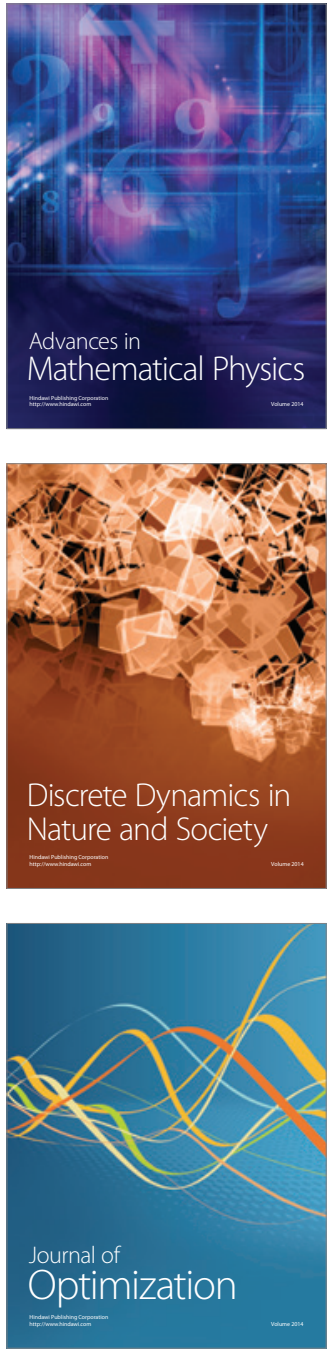